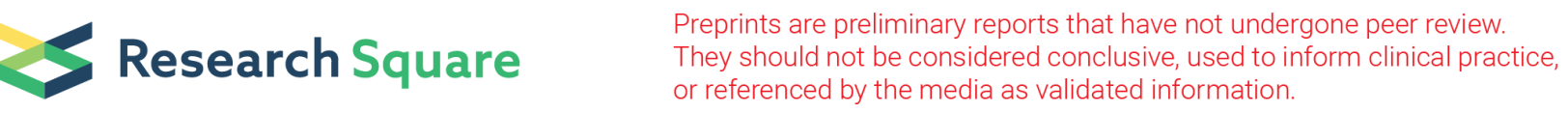

\title{
Simultaneous Bilateral Total Knee Arthroplasty Retrospective Case Control Study: Does Genicular Injection Application Yield a More Effective Pain Control Compared with Periarticular Injection?
}

Abdullah Küçükalp ( $\square$ karalama76@gmail.com )

Hayat Private Hospital https://orcid.org/0000-0002-1290-6059

Bülent Özdemir

Private Medline Hospital

Research article

Keywords: Genicular Injection, Periarticular Injection, Bilateral Knee Arthroplasty, Multimodal Analgesia

Posted Date: November 2nd, 2021

DOI: https://doi.org/10.21203/rs.3.rs-922089/v1

License: (c) (1) This work is licensed under a Creative Commons Attribution 4.0 International License. Read Full License 


\section{Abstract}

Background:

The aim of the present study was to investigate the hypothesis that administering the analgesic solution prepared for periarticular injection as a genicular injection to patients undergoing bilateral knee arthroplasty has equivalent effect to periarticuler injection and provides equal or enhanced pain control. Thus, these two different practices were compared.

Methods:

This was a case control study, during which simultaneous bilateral knee arthroplasty patients were evaluated retrospectively. The analgesic solution prepared for periarticular injection was applied as a genicular injection to one knee of each of 30 patients operated on in the same session, and was applied as standard periarticular injection to the other knee. The study group comprised the patients operated on in the same session who were subject to genicular infiltration anaesthesia and the control group consisted of patients with standard periarticular infiltration anaesthesia administered to the other knee. The study data are summarized via descriptive statistics (mean, standard deviation, etc.). Statistical analyses were performed using SPSS 22.0 software. Wilcoxon's signed-rank test was used for comparisons. The level of statistical significance was set at $p<0,05$.

Results:

Pain scores were lower during the early postoperative period in the knees of patients who received the genicular injection ( $<<0.005)$. There were no statistically significant differences between the groups with regard to drainage volume, complications and range of joint motion.

Conclusions:

Genicular injection is a reliable and effective procedure for early postoperative pain control.

\section{Introduction}

It has been illustrated in the literature that simultaneous bilateral total knee arthroplasty (TKA) can be applied reliably in patients with pain and limitations in both knees whose health status is suitable for simultaneous bilateral (TKA) $(1,2)$. Various treatment modalities are applied for pain control after TKA. Periarticular injection (PAI) is one of these applications and is routinely implemented during TKA surgery. PAI has been proven to be effective against pain and provides functional results (3). PAl is also commonly used as a reference application in control groups in comparative studies evaluating other approaches (4-7). Genicular block application via ultrasonography and/or scopy along with radiofrequency ablation treatment provides satisfactory results in patients undergoing osteoarthritis treatment without TKA and for the treatment of painful knee prostheses in patients who underwent TKA (8-11). PAI is applied to the posterior capsule collateral bonds and soft tissues surrounding the joint. Pain these tissues arises from the genicular nerves $(12,13)$. The present study tested the hypothesis that administering a commonplace anaesthetic cocktail to bilateral knee arthroplasty patients as a genicular injection is equivalent to periarticuler injection and provides equal or more effective pain control. Thus, these two different practices were compared.

\section{Materials And Method}

\section{Study design and population}

The present study was a case-control study during which simultaneous bilateral knee arthroplasty patients treated between December 2019 and March 2020 were evaluated retrospectively. The study group comprised patients operated on in the same session who were subject to genicular infiltration anaesthesia and the control group consisted of patients with standard periarticular infiltration anaesthesia administered to the other knee. A total of 46 patient files were evaluated during the study. A total of 60 knees (experiment group: 15 right knees, 15 left knees with genicular injection; control group: 15 right knees, 15 left knees) of 30 patients (mean age: $63.47 \pm 7.09$, female/male $22 / 8$ ) with primary osteoarthritis administered with single-dose spinal anaesthesia who were suitable for simultaneous bilateral TKA were evaluated during the study. The exclusion criteria were as follows: Patients with flexion contracture exceeding $20^{\circ}$ and knee flexion less than $90^{\circ}$, with varus sequence of above $20^{\circ}$, with secondary osteoarthritis, with inflammatory arthritis, who could not undergo spinal anaesthesia, diabetic patients with HA1C > 10, those without follow up information, patients with heart failure or cerebrovascular problems with deep vein thrombosis or severe venous failure, patients with chronic polyneuropathy at the lower extremity, patients with neurologic deficit, patients with $\mathrm{Hb}$ values of less than 9 $\mathrm{mg} / \mathrm{dl}$ along and patients unable to receive clinical follow up. The present study was carried out in accordance with the Helsinki Declaration Principles after obtaining the required approvals from the local Ethics Council subject to the decree 2020-10/9, dated June 10, 2020. There were no conflicts of interest in this study. 


\section{Surgical intervention and assessment}

All patients were administered 40 mg enoxaparin sodium 12 hours prior to the surgery. A total of 1000 ml balanced electrolyte solution was administered to the patients for hydration purposes starting at the preoperative 8th hour. Prophylactic $1 \mathrm{~g}$ cefazolin sodium was administered approximately 30 minutes before the surgery. All surgical procedures were conducted by the same surgeon. A urinary catheter was inserted into all patients following the spinal anaesthesia procedure with pneumatic tourniquets wrapped around both extremities. The pneumatic tourniquet was inflated up to a pressure of $275 \mathrm{~mm}-\mathrm{Hg}$ in a sterile environment, after which TKA was conducted via standard midline incision and medial parapetallar arthrotomy. Fixed insert, posterior stabilised design prostheses were used in all patients (Anthem (Smith+Nephew $\left.{ }^{\circledR}\right)$, Columbus ${ }^{\circledR}$ (Braun)). The analgesic cocktail mixture consisted of $100 \mathrm{mg}$ bupivacaine (\% 0.5, $20 \mathrm{~mL}), 40 \mathrm{mg}$ methylprednisolone (2 mL), $300 \mathrm{mg} \mathrm{1:1000}$ epinephrine $(0.3 \mathrm{~mL}), 750 \mathrm{mg}$ cefuroxime axetil $(10 \mathrm{~mL})$ and $1 \mathrm{mg}$ morphine sulfate $(0.1 \mathrm{~mL})$. The solution was brought to a volume of $60 \mathrm{~mL}$ using sterile normal saline solution. After the bone incisions and soft tissue releases were completed, a decision was made for the length of the prostheses using prostheses mock ups followed by the implantation of the prostheses to the experiment group with $20 \mathrm{ml}$ analgesic cocktail applied to approximately $3 \mathrm{~cm}$ proximal of the femur medial and lateral condyles, which are the genicular nerve locations as defined in the literature, to the superior medial and lateral genicular nerve and to approximately $4 \mathrm{~cm}$ distal of the medial proximal tibia joint line, to the centre of the inferior medial genicular perineural area (Photo 1). Twenty millilitres was injected into the control group prior to prosthesis implantation, and $10 \mathrm{ml}$ was injected into the soft tissue surrounding the medial and lateral collateral bonds after prosthesis implantation into the posterior capsule. The remainder was applied to the quadriceps muscle, joint capsule and subcutaneous tissues after the capsule was closed. Prior to placing the vacuum drain bellows subcutaneously and after closing off the skin, 2 gr tranexamic acid was administered to the joint via the drain, after which the drain was clamped, and the vacuum bellows was placed. Elastic bandages were applied to both lower extremities. All drains were opened at the 3rd hour after the surgery without vacuuming, and the drains were removed one day later. Range of joint motion (JRM) exercises were started immediately after the patient was transferred to the service bed with 20 passive repetitions per hour. The knee pump exercise and femur set and straight leg lift exercises were performed 20 times each per hour. The patients were mobile in their rooms by using walkers. The patients were woken up a minimum of 4 times during the first night after the surgery and were asked to walk for as long as they could tolerate. The drains and urinary catheter were removed during the first day after surgery. Medical dressings were applied, and the patients wore knee compression socks. Prophylactic antibiotic administration was completed after 48 hours. Acetaminophen (1000 mg) was administered intravenously for 8 hours for analgesia after the surgery throughout the period that the patient was hospitalized. Patients with visual analog scale (VAS) scores that were greater than five were administered petidine hydrochloride at $1 \mathrm{mg}$ per kilogram. The patients were routinely administered $2000 \mathrm{~mL}$ balanced electrolyte solution preoperatively and postoperatively for one day. The patients were administered $40 \mathrm{mg}$ enoxaparin sodium throughout their hospitalization periods as venous thromboembolic prophylaxy. Postoperative drainage volume and pain assessments were by service nurses blinded to patient groups who conducted VAS assessments using a VAS range from 0 mm (indicates no pain) to $10 \mathrm{~mm}$ (indicates excessive pain) with $1 \mathrm{~mm}$ increments. VAS pain scores were measured while the patients rested and while they were exercising on postoperative day 0 (2nd and 8th hours), the first and second days and the first postoperative month. Active EHA for both knee joints was measured during the preoperative period and on the postoperative first and second days. Other data were acquired from the hospital record system. All patients were discharged on the second postoperative day. The patients were told not use a medical dressing in case of leakage from the scar site, and they were prescribed $250 \mathrm{mg}$ paracetamol, $150 \mathrm{mg}$ propifenazon combined with $3 \star 1$ of $50 \mathrm{mg}$ caffeine tablets, Lansaprazol $30 \mathrm{mg} 1 * 1$, naproxen Na $550 \mathrm{mg}$ combined with $30 \mathrm{mg}$ codeine phosphate $2 \star 1$, and enteric coated $150 \mathrm{mg}$ acetylsalicylic acid tablets $2 * 1$. All patients were assessed on the 15th postoperative day, and their sutures were removed. The patients were subjected to the required blood tests as well as assessments of JRM and pain during the 1st postoperative month. The study data are summarized via descriptive statistics (mean, standard deviation, etc.). Statistical analyses were performed using SPSS 22.0 software. Wilcoxon's signed-rank test was used for comparisons. The level of statistical significance was set at $p<0,05$.

\section{Results}

A total of 60 knees of 30 patients were evaluated during the present study. Table 1 presents the demographic data of the patients. Surface or deep infection, deep vein thrombosis, major haemorrhage and pulmonary emboli were not observed in any of the patients during the final followup.

Table 1

Demographic data for the patients 


\begin{tabular}{|ll|}
\hline Demographic Data for the Patients & Mean \pm Standard Deviation \\
\hline Age & $63.47 \pm 7.09$ \\
Height & $161.90 \pm 6.78$ \\
\hline Weight & $84.47 \pm 9.98$ \\
\hline Body Mass Index & $32,23 \pm 3.26$ \\
\hline
\end{tabular}

The mean drainage was $269 \pm 58.33 \mathrm{ml}$ from the right knees and 263,67 $\pm 54,55 \mathrm{ml}$ from the left knees. Statistically significant differences were not observed between the experimental and control groups with regard to drainage volume $(p=0.707)$. Table 2 shows the preoperative and postoperative laboratory value distribution for the patients.

Table 2

Preoperative and postoperative laboratory value distribution for the patients

\begin{tabular}{|llll|}
\hline Laboratory Distributions & Preoperative & Postoperative Day 1 & Postoperative Month 1 \\
\hline Haemoglobin $(\mathrm{Hb} \mathrm{g} / \mathrm{dl})$ & $13,24 \pm 1,54$ & $10,82 \pm 1,45$ & $11,37 \pm 1,47$ \\
\hline Haematocrit $(\mathrm{Htc} \%)$ & $40,33 \pm 3,85$ & $33,15 \pm 4,10$ & $34,96 \pm 4,08$ \\
\hline Sedimentation $(\mathrm{mm} / \mathrm{s})$ & $21.50 \pm 14.82$ & $28.37 \pm 12.63$ & $35.40 \pm 17.04$ \\
\hline Crp $(\mathrm{mg} / \mathrm{l})$ & $5.28 \pm 3.88$ & $52.76 \pm 22.64$ & $12.49 \pm 14.59$ \\
\hline
\end{tabular}

As shown in Table 3, a statistically significant difference was not identified between the experimental and control groups with regard to EHA (1st month comparison $\mathrm{p}=0.190)$. Graph 1 shows the EHA time distribution graph.

Table 3

Preoperative and postoperative EHA distributions for the patients

\begin{tabular}{|c|c|c|c|c|c|c|c|c|}
\hline \multicolumn{9}{|c|}{ Range of Joint Motion } \\
\hline & \multicolumn{2}{|l|}{ Preoperative } & \multicolumn{2}{|c|}{ Postoperative Day 1} & \multicolumn{2}{|c|}{ Postoperative Day 2} & \multicolumn{2}{|c|}{ Postoperative Month 1} \\
\hline & Flexion & Extension & Flexion & Extension & Flexion & Extension & Flexion & Extension \\
\hline Experiment & $106.00 \pm 10.37^{\circ}$ & $-8 \pm 6.10^{\circ}$ & $89.33 \pm 10.06^{\circ}$ & $-2.00 \pm 3.37^{\circ}$ & $94.67 \pm 9.91^{\circ}$ & $-1.33 \pm 2.25^{\circ}$ & $113.17 \pm 8.25^{\circ}$ & $-0.83 \pm 1.90$ \\
\hline Control & $106.00 \pm 10.37^{\circ}$ & $-8 \pm 4.07^{\circ}$ & $90.17 \pm 10.71^{\circ}$ & $-2.00 \pm 3.37^{\circ}$ & $94.00 \pm 9.04^{\circ}$ & $-1.33 \pm 2.25^{\circ}$ & $114.00 \pm 8.24^{\circ}$ & $-0.83 \pm 1.90^{\circ}$ \\
\hline
\end{tabular}

Graph 1: JRM over time

The statistical assessment showed that the VAS scores were low at a statistically significant level $(p=0.000)$ in the static and dynamic measurements in the experimental group at 2 and 8 hours postoperatively. Pain scores during the postoperative first day assessments were observed to be low at a statistically significant level for static measurements $(p=0.005)$ and dynamic measurements ( $p=0.000)$. A statistically significant difference was not observed between the VAS measurements of the experiment and control groups during the postoperative second day in either the static measurements $(p=0.317)$ or the dynamic measurements $(p=0.157)$. Similarly, there were no statistically significant differences between the two groups with regard to VAS measurements conducted in the first month $(p=0.965)$. Table 4 shows the static and dynamic distributions of the VAS scores for both groups together with the standard deviation values.

Table 4

Distribution of VAS scores of patients in the experimental and control groups 


\begin{tabular}{|c|c|c|c|c|}
\hline & \multicolumn{4}{|l|}{ VAS Score } \\
\hline & \multicolumn{2}{|l|}{ Control } & \multicolumn{2}{|l|}{ Experiment } \\
\hline & Static & Dynamic & Static & Dynamic \\
\hline Postoperative $2^{\text {nd }}$ Hour & $1.47 \pm 0.78$ & $3.03 \pm 1.07$ & $0.97 \pm 0.61$ & $2.23 \pm 0.90$ \\
\hline Postoperative $8^{\text {th }}$ Hour & $1.90 \pm 0.71$ & $3.97 \pm 1.50$ & $1.30 \pm 0.65$ & $3.03 \pm 1.22$ \\
\hline Postoperative $1^{\text {st }}$ day & $2.20 \pm 0.55$ & $4.70 \pm 0.60$ & $1.93 \pm 0.37$ & $4.00 \pm 0.59$ \\
\hline Postoperative $2^{\text {nd }}$ day & $1.83 \pm 0.46$ & $3.73 \pm 0.69$ & $1.80 \pm 0.48$ & $3.67 \pm 0.66$ \\
\hline Postoperative $1^{\text {st }}$ month & $0.96 \pm 0.65$ & $2.25 \pm 0.75$ & $0.97 \pm 0.56$ & $2.28 \pm 0.65$ \\
\hline
\end{tabular}

Graph 2 Postoperative time graph of VAS scores

Graph 2 shows the postoperative changes in the mean values of the control and experimental groups subject to time for VAS scores.

\section{Discussion}

Simultaneous bilateral TKA is a procedure that can be applied safely to patients with arthrosis after taking into consideration their clinical complaints and systemic health status. Liu L et al. (14) conducted a meta-analysis during which they evaluated 18 studies that complied with the includsion criteria and reported that even though deep infection and respiratory complications were observed less frequently with simultaneous bilateral TKA application, the rates of mortality, deep vein thrombosis and pulmonary emboli were higher than those with the staged bilateral TKA procedure, thus suggesting procedure selection on a patient-by-patient basis. Patient selection criteria were identified based on these criteria during the present study, with a simultaneous bilateral TKA procedure applied to suitable patients. No early local or systemic complications were observed in the patients who underwent this procedure.

Cheng KY et al. carried out a study during which they administered analgesic cocktails via periarticular injection to one knee and via intraarticular injection to the other knee of patients who underwent bilateral knee arthroplasty in the same session, thus conducting a randomized controlled study (15). In another study, the authors classified patients who underwent simultaneous bilateral knee arthroplasty into two groups, injected the PAI solution in a randomized manner to the rear or front compartments, and compared the pain and functional results (16). In the present study, we also injected the prepared analgesic cocktail into the genicular nerves in one knee and into the standard periarticular injection regions in the other knee to assess the pain and functional results. We believe that the present study is of significant importance since it is the first study comparing genicular injection procedures.

Dhillon MS. et al. (17) conducted a comparative study of 108 patients who underwent simultaneous bilateral TKA, and they reported that the use of intravenous transanaemic acid led to $562 \mathrm{ml}$ lower drainage in the experimental group compared with that in the control group; the drainage values were $247,63 \pm 128.34 \mathrm{ml}$ on average in the experimental group and $809.64 \pm 227.3 \mathrm{ml}$ in the control group. In another study by Kelly et al. (18), 121 patients were subjected to simultaneous bilateral TKA and the use of intravenous transanaemic acid led to less drainage by 497.80 ml on average in the experimental group compared with that in the control group; the average drainage values were $373.8 \pm 294.6 \mathrm{ml}$ in the experimental group and $871.6 \pm 457.7 \mathrm{ml}$ in the control group. Mao Z. et al. (19) carried out a study comparing periarticular and intraarticular transanaemic acid application with a control group, and they indicated that they removed the drains from the intraarticular transanaemic acid group at $42.6 \pm 13$ hours and reported a drainage amount of $305.0 \pm 169.1 \mathrm{ml}$. Transanaemic acid was administered via intraarticular injection to the experimental and control groups, and the mean drainage drawn from the right and left knees was $269 \pm 58.33 \mathrm{ml}$ and $263,67 \pm 54,55 \mathrm{ml}$, respectively. We believe that less drainage was observed in the present study compared with that observed after intravenous application of transanaemic acid in previous studies, and the intraarticular application was related to local application in addition to keeping the drain closed postoperatively for three hours, a follow-up period without vacuum, and removal before 24 hours.

PAl administered to the joint capsule and its surroundings reduces postoperative pain scores while also increasing patient satisfaction. Moreover, this approach helps us to avoid the neurological complications that may be caused by peripheral nerve blocks in addition to enabling us to conduct early rehabilitation work with the patients $(20,21)$. Fan L. et al. (22) carried out a randomized prospective study comparing PAI and femoral nerve block (FNB) during which they reported neuropraxic damage in a patient subject to FNB, and no statistically significant difference was identified in the patients' pain levels. In another study, Andersen HL. Et al. (23) examined the results of a peripheral nerve block accompanied with PAI in which they reported postoperative four-month-long paraesthesia that emerged following the development of a haematoma in the saphenous nerve tract immediately after the removal of the catheter, and the onset of aspiration pneumonia in another patient. Peripheral nerve block is not as safe as PAl due to the risk for such complications. Zhang LK et al. (24) carried out a meta-analysis study comparing PAI and FNB applications through the comparison of 10 randomized controlled studies, and they reported that no statistically 
significant difference could be identified in 950 patients with regard to pain scores, EHA, complications and hospitalization durations, thereby concluding that the two applications have similar efficacy. The aim of the present study was to examine whether PAI application with proven efficacy and reliability can be used more effectively. Sun J. et al. (25) conducted a retrospective comparative study in which they assessed the pain levels in the first operated knee treated with PAl and in the second operated knee that was not subject to PAI application in the same session and measured VAS scores ranging from 0-100. They reported the 24th hour VAS to be static 44 and dynamic 78 for the first knee, and static 52 and dynamic 83 for the second knee; at the eighth hour, the VAS static score was 35 and the dynamic score was 75 for the first knee, and 40 and 77, respectively, for the second knee. Mullaji A et al. (26) carried out a randomized prospective study in which PAl was applied to one knee of the patients who underwent simultaneous bilateral knee arthroplasty, whereas they did not apply PAl to the other knee. The VAS scores were assessed with a range of $0-10$, and the pain scores for the knee with PAI application and the knee without PAI application were 2.3 - 5 on the day of the surgery, $3.3-6.3$ on the first postoperative day, $2.6-4.6$ on the day of discharge and $1-2.4$ after the first month. The EHA assessments reported in this study revealed that there was a functional difference at a statistically significant level between the experimental and control groups during the first month of follow-up, which was suggested to result from PAI. VAS assessment was conducted with a range of 0-10 in the present study, with results for the experimental and control groups having an average VAS statistic of 2.20 (dynamic) 4.70 (static) and 1.9 (dynamic) 4.00 (static) on the first day and 1.8 (static) and 3.7 (dynamic); 1.8 (static) and 3.6 (dynamic), respectively, on the second day. As seen in Table 4, pain scores were observed to be low at a statistically significant level on the 2nd and 8th hours after surgery and on the first day after surgery in patients subject to genicular nerve block $(p=0.005)$. Thus, genicular nerve block application can be an alternative to standard PAI application during the early postoperative period due to the lower pain scores. Laoruengthana A et al. carried out a randomized prospective study in which they utilized sealed envelope randomization on patients who underwent simultaneous bilateral knee arthroplasty under spinal anaesthesia, classifying their knees into groups A and B and injecting $20 \mathrm{ml}$ of the prepared PAl into the medial retinaculum and pes anserinusa, $25 \mathrm{ml}$ into the quadriceps muscle and $5 \mathrm{ml}$ into the retropatellar fat tissue in group A. In group B, they injected $10 \mathrm{ml}$ into the medial rear capsule, $10 \mathrm{ml}$ into the lateral rear capsule, $5 \mathrm{ml}$ into the medial collateral ligament, $15 \mathrm{ml}$ into the residual medial meniscus and $15 \mathrm{ml}$ into the lateral collateral ligament and residual lateral meniscus. The same postoperative medical treatment protocol was applied to all patients, mobilizing the patients using passive movements and walkers continuously from postoperative day one. The pain scores in group A were observed to be significantly lower than those in group B on the first two days; however, similar results were obtained during the 2 nd and 6 th week follow-ups. A statistically significant difference was not identified with regard to blood loss, maximum knee flexion or active flexion angles (16). While the pain scores on the day of the operation and postoperative first day were low at a statistically significant level in our study for patients subjected to genicular application, statistically significant differences could not be observed in other parameters. Tsukada $\mathrm{S}$ et al. conducted a randomized controlled study in which they compared PAI and epidural analgesia in patients subjected to the same surgical technique under spinal anaesthesia who were followed up with the same medical treatment protocol, and they reported that PAI application provided better pain control during the early postoperative period in addition to earlier recovery with regard to the knee flexion angle. The group subjected to PAI with a preoperative mean knee flexion angle of $120^{\circ}$ reached flexion openings of $65^{\circ}$ on the first day, $70^{\circ}$ on the second day and $110^{\circ}$ on the first month (27). The average JRM was $106^{\circ}$ for the experiment and control groups prior to the operation and reached $90^{\circ}$ on postoperative day one, $94^{\circ}$ on postoperative day two and $114^{\circ}$ on the first month. We believe that the earlier recovery in the flexion angle was due to less haemorrhage related to the use of transanaemic acid and the positive impact of early active and passive rehabilitation. Iwakiri K. et al. carried out a randomized controlled study comparing the results of active and passive rehabilitation on the first postoperative day and on the seventh day. They administered $1 \mathrm{gr}$ tranexamic intravenously under general anaesthesia, after which they injected 2 gr tranexamic acid intraarticularly after closing the joint capsule and applied PAl for pain control following prosthesis implantation. As a result, they identified lower pain scores on the 18th and 72nd hours at a statistically significant level in the early rehabilitation group and observed no statistically significant difference between the two groups with regard to JRM. They also reported that they could not obtain the preoperative flexion values during the first month of follow-up (28). Pain scores at rest on postoperative days were observed to decrease distinctively in the present study when active and passive rehabilitation was started at postoperative day zero and was continued hourly on the following days. We were able to attain an average improvement of $8^{\circ}$ in the flexion angles in the postoperative first month after beginning rehabilitation early.

\section{Conclusion}

Genicular injection is equivalent to the standard PAI application with regard to the ease of the surgical operation, the level of haemorrhage, the impact on the JRM and the incidence of local complications; thus, genicular injection can be considered a simple and reliable technique that is more effective for early postoperative pain than the standard application. Further randomized prospective studies are required to further assess its effectiveness.

\section{Abbreviations}

TKA: Total Knee Arthroplasty

PAl: Periarticular Injection 


\section{Declarations}

\section{Availability of data and materials}

The data and materials used and/or analyzed during the current study are not publicly available but available from the corresponding author on reasonable request.

\section{Ethics approval and consent to participate}

This study was approved by the ethics committee at Uludag University Faculty of Medicine Ethics Council subject to the decree 2020-10/9, dated June 10, 2020.

\section{Consent for publication}

Written informed consent was obtained from all participants.

\section{Competing interests}

The authors declare that they have no competing interests.

\section{Acknowledgements}

Not applicable.

\section{Funding}

No funding was received for this study.

\section{Contributions}

Study design was carried out by AK and BÖ. Study conduct was done by AK and BÖ. Data collection was done by AK and BÖ. Data interpretation was carried out by AK and BÖ. Drafting manuscript was done by AK and BÖ. AK takes responsibility for the integrity of the data analysis. All authors have read and approved the manuscript.

\section{References}

1. Leonard L, Williamson D, Ivory J, Jennison C. An evaluation of the safety and efficacy of simultaneous bilateral total knee arthroplasty. J Arthroplasty. 2003;18:972-8.

2. Restrepo C, Parvizi J, Dietrich T, Einhorn TA. Safety of simultaneous bilateral total knee arthroplasty. J Bone Joint Surg Am. 2007;89:12206.

3. Maheshwari AV, Blum YC, Shekhar L, Ranawat AS, Ranawat CS. Multimodal pain management after total hip and knee arthroplasty at the Ranawat Orthopaedic Center. Clin Orthop Relat Res. 2009 Jun;467(6):1418-23. doi:10.1007/s11999-009-0728-7. Epub 2009 Feb 13. PMID: 19214642; PMCID: PMC2674168.

4. Deng Z, Li Y, Storm GR, Kotian RN, Sun X, Lei G, Gao S, Lu W. The efficiency and safety of steroid addition to multimodal cocktail periarticular injection in knee joint arthroplasty: a meta-analysis of randomized controlled trials. Sci Rep. 2019 May 7;9(1):7031. doi: 10.1038/s41598-019-43540-9. PMID: 31065018; PMCID: PMC6505038.

5. Mullaji A, Kanna R, Shetty GM, Chavda V, Singh DP. Efficacy of periarticular injection of bupivacaine, fentanyl, and methylprednisolone in total knee arthroplasty:a prospective, randomized trial. J Arthroplasty. 2010 Sep;25(6):851-7. doi:10.1016/j.arth.2009.09.007. Epub 2009 Dec 21. PMID: 20022457. 
6. Hyland SJ, Deliberato DG, Fada RA, Romanelli MJ, Collins CL, Wasielewski RC. Liposomal Bupivacaine Versus Standard Periarticular Injection in Total Knee Arthroplasty With Regional Anesthesia: A Prospective Randomized Controlled Trial. J Arthroplasty. 2019 Mar;34(3):488-94. doi: 10.1016/j.arth.2018.11.026. Epub 2018 Nov 23. PMID: 30554925.

7. Liu Y, Zeng Y, Zeng J, Li M, Wei W, Shen B. The efficacy of liposomal bupivacaine compared with traditional peri-articular injection for pain control following total knee arthroplasty: an updated meta-analysis of randomized controlled trials. BMC Musculoskelet Disord. 2019 Jun 29;20(1):306. doi: 10.1186/s12891-019-2660-7. PMID: 31253119; PMCID: PMC6599357.

8. Qudsi-Sinclair S, Borrás-Rubio E, Abellan-Guillén JF, Padilla Del Rey ML, Ruiz-Merino G. A Comparison of Genicular Nerve Treatment Using Either Radiofrequency or Analgesic Block with Corticosteroid for Pain after a Total Knee Arthroplasty: A Double-Blind, Randomized Clinical Study. Pain Pract. 2017 Jun;17(5):578-588. doi: 10.1111/papr.12481. Epub 2016 Sep 19. PMID: 27641918.

9. Ariel de Lima D, Gonçalves MCK, Grando STCES, Cintra TLL, Pinto DM, Gonçalves RK. Indications of the Neurotomy of Genicular Nerves by Radiofrequency for the Treatment of Knee Osteoarthritis: A Literature Review. Rev Bras Ortop (Sao Paulo). 2019 May;54(3):233-40. doi:10.1055/s-0039-1692121. Epub 2019 Jun 27. PMID: 31363275; PMCID: PMC6597460.

10. El-Hakeim EH, Elawamy A, Kamel EZ, Goma SH, Gamal RM, Ghandour AM, Osman AM, Morsy KM. Fluoroscopic Guided Radiofrequency of Genicular Nerves for Pain Alleviation in Chronic Knee Osteoarthritis: A Single-Blind Randomized Controlled Trial. Pain Physician. 2018 Mar;21(2):169-77. PMID: 29565947.

11. Kim DH, Choi SS, Yoon SH, Lee SH, Seo DK, Lee IG, Choi WJ, Shin JW. Ultrasound-Guided Genicular Nerve Block for Knee Osteoarthritis: A Double-Blind, Randomized Controlled Trial of Local Anesthetic Alone or in Combination with Corticosteroid. Pain Physician. 2018 Jan;21(1):41-52. PMID: 29357330.

12. Franco CD, Buvanendran A, Petersohn JD, Menzies RD, Menzies LP. Innervation of the Anterior Capsule of the Human Knee: Implications for Radiofrequency Ablation. Reg Anesth Pain Med. 2015 Jul-Aug;40(4):363-8. doi: 10.1097/AAP.0000000000000269. PMID: 26066383.

13. Tran J, Peng P, Agur A. Evaluation of nerve capture using classical landmarks for genicular nerve radiofrequency ablation: 3D cadaveric study. Reg Anesth Pain Med. 2020 Nov;45(11):898-906. doi:10.1136/rapm-2020-101894. Epub 2020 Sep 14. PMID: 32928998.

14. Liu L, Liu H, Zhang H, Song J, Zhang L. Bilateral total knee arthroplasty: Simultaneous or staged? A systematic review and meta-analysis. Medicine. 2019 May;98(22):e15931. doi:10.1097/MD.0000000000015931. PMID: 31145362; PMCID: PMC6708906.

15. Cheng KY, Feng B, Peng HM, Bian YY, Zhang LJ, Han C, Qiu GX, Weng X. The analgesic efficacy and safety of peri-articular injection versus intra-articular injection in one-stage bilateral total knee arthroplasty: a randomized controlled trial. BMC Anesthesiol. 2020 Jan 4;20(1):2. doi: 10.1186/s12871-019-0922-4. PMID: 31901229; PMCID: PMC6942284.

16. Laoruengthana A, Rattanaprichavej P, Rasamimongkol S, Galassi M. Anterior vs Posterior Periarticular Multimodal Drug Injections: A Randomized, Controlled Trial in Simultaneous Bilateral Total Knee Arthroplasty. J Arthroplasty. 2017 Jul;32(7):2100-4. doi:10.1016/j.arth.2017.02.033. Epub 2017 Feb 24. PMID: 28318865.

17. Dhillon MS, Bali K, Prabhakar S. Tranexamic acid for control of blood loss in bilateral total knee replacement in a single stage. Indian $\mathrm{J}$ Orthop. 2011 Mar;45(2):148-52. doi:10.4103/0019-5413.77135. PMID: 21430870; PMCID: PMC3051122.

18. Kelley TC, Tucker KK, Adams MJ, Dalury DF. Use of tranexamic acid results in decreased blood loss and decreased transfusions in patients undergoing staged bilateral total knee arthroplasty. Transfusion. 2014 Jan;54(1):26-30. doi:10.1111/trf.12167. Epub 2013 Mar 22. PMID: 23521109.

19. Mao Z, Yue B, Wang Y, Yan M, Dai K. A comparative, retrospective study of peri-articular and intra-articular injection of tranexamic acid for the management of postoperative blood loss after total knee arthroplasty. BMC Musculoskelet Disord. 2016 Oct 19;17(1):438. doi: 10.1186/s12891-016-1293-3. PMID: 27760536; PMCID: PMC5069893.

20. Goyal N, McKenzie J, Sharkey PF, Parvizi J, Hozack WJ, Austin MS. The 2012 Chitranjan Ranawat award: intraarticular analgesia after TKA reduces pain: arandomized, double-blinded, placebo-controlled, prospective study. Clin Orthopaedics Relat Res. 2012;471:64e75.

21. Springer BD, Mason JB, Odum SM. Systemic Safety of Liposomal Bupivacaine in Simultaneous Bilateral Total Knee Arthroplasty. J Arthroplasty. 2018 Jan;33(1):97-101. doi:10.1016/j.arth.2017.07.038. Epub 2017 Aug 1. PMID: 28844768.

22. Fan L, Yu X, Zan P, Liu J, Ji T, Li G. Comparison of Local Infiltration Analgesia With Femoral Nerve Block for Total Knee Arthroplasty: A Prospective, Randomized Clinical Trial. J Arthroplasty. 2016 Jun;31(6):1361-5. doi: 10.1016/j.arth.2015.12.028. Epub 2015 Dec 20. PMID: 26810604.

23. Andersen HL, Gyrn J, Møller L, Christensen B, Zaric D. Continuous saphenous nerve block as supplement to single-dose local infiltration analgesia for postoperative pain management after total knee arthroplasty. Reg Anesth Pain Med. 2013 Mar-Apr;38(2):106-11. doi: 10.1097/AAP.0b013e31827900a9. PMID: 23222363.

24. Zhang LK, Ma JX, Kuang MJ, Ma XL. Comparison of Periarticular Local Infiltration Analgesia With Femoral Nerve Block for Total Knee Arthroplasty: a Meta-Analysis of Randomized Controlled Trials. J Arthroplasty. 2018 Jun;33(6):1972-1978.e4. doi: 10.1016/j.arth.2017.12.042. Epub 2018 Jan 11. PMID: 29455938.

Page $8 / 11$ 
25. Sun J, Li L, Yuan S, Zhou Y. Analysis of Early Postoperative Pain in the First and Second Knee in Staged Bilateral Total Knee Arthroplasty: A Retrospective Controlled Study. PLoS One. 2015;10(6):e0129973. doi:10.1371/journal.pone.0129973. Published 2015 Jun 11.

26. Mullaji A, Kanna R, Shetty GM, Chavda V, Singh DP. Efficacy of periarticular injection of bupivacaine, fentanyl, and methylprednisolone in total knee arthroplasty:a prospective, randomized trial. J Arthroplasty. 2010 Sep;25(6):851-7. doi:10.1016/j.arth.2009.09.007. Epub 2009 Dec 21. PMID: 20022457.

27. Tsukada S, Wakui M, Hoshino A. Postoperative epidural analgesia compared with intraoperative periarticular injection for pain control following total knee arthroplasty under spinal anesthesia: a randomized controlled trial. J Bone Joint Surg Am. 2014 Sep 3;96(17):1433-8. doi: 10.2106/JBJS.M.01098. PMID: 25187581.

28. Iwakiri K, Ohta Y, Shibata Y, Minoda Y, Kobayashi A, Nakamura H. Initiating range of motion exercises within 24 hours following total knee arthroplasty affects the reduction of postoperative pain: A randomized controlled trial. Asia Pac J Sports Med Arthrosc Rehabil Technol. 2020 Apr 28;21:11-16. doi: 10.1016/j.asmart.2020.03.003. PMID: 32373475; PMCID: PMC7191316.

\section{Figures}

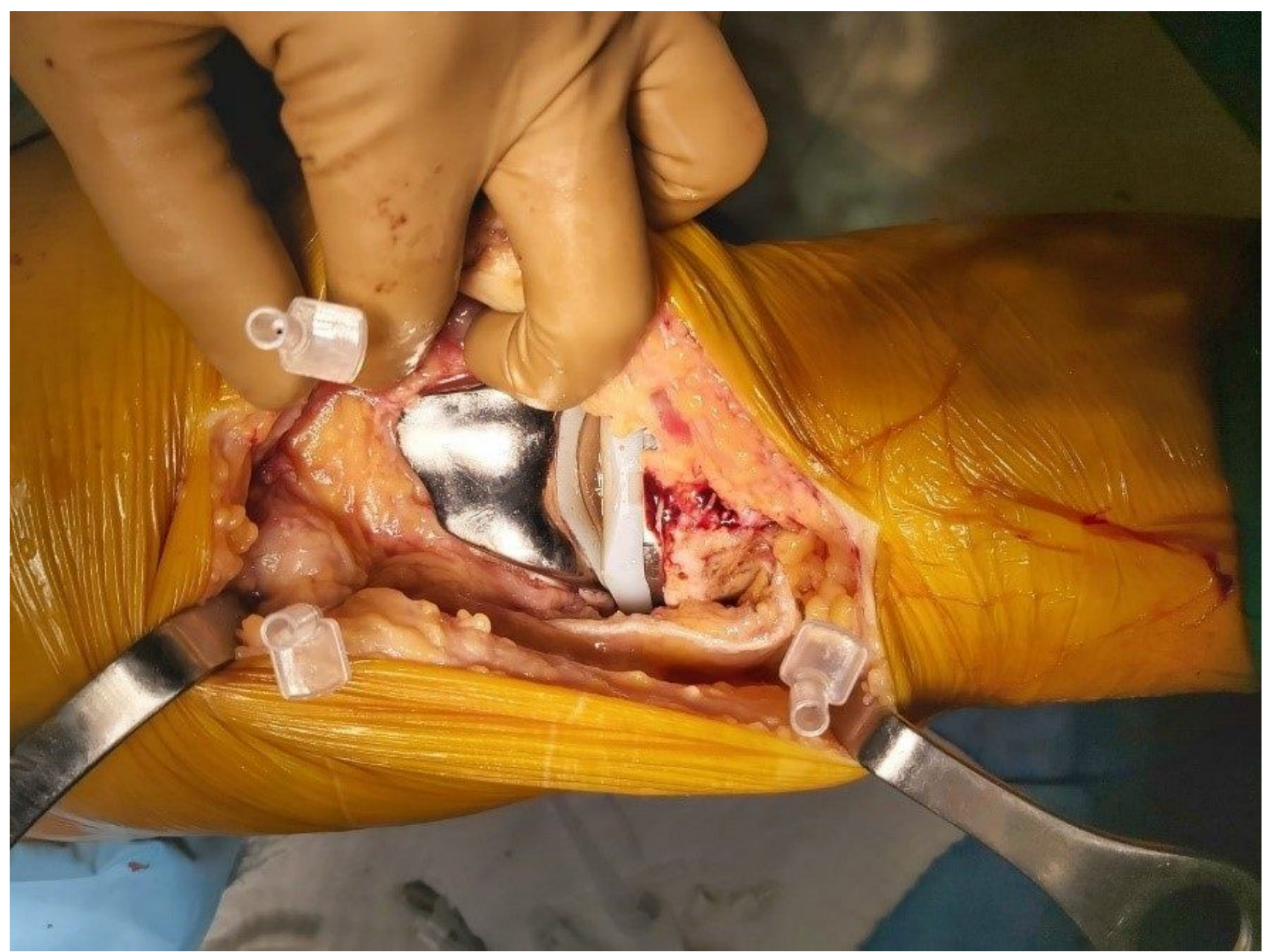

\section{Figure 1}

Photo 1: Genicular injection application points 


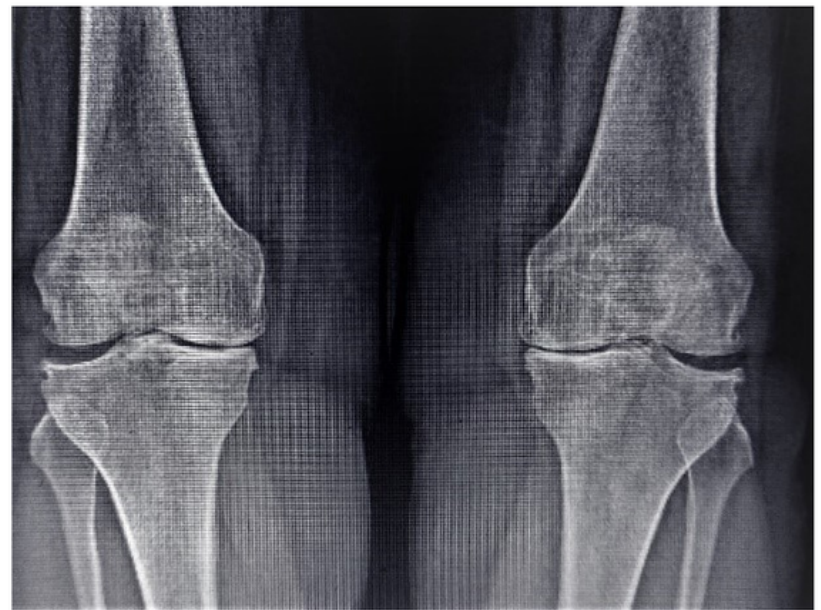

$\mathbf{a}$

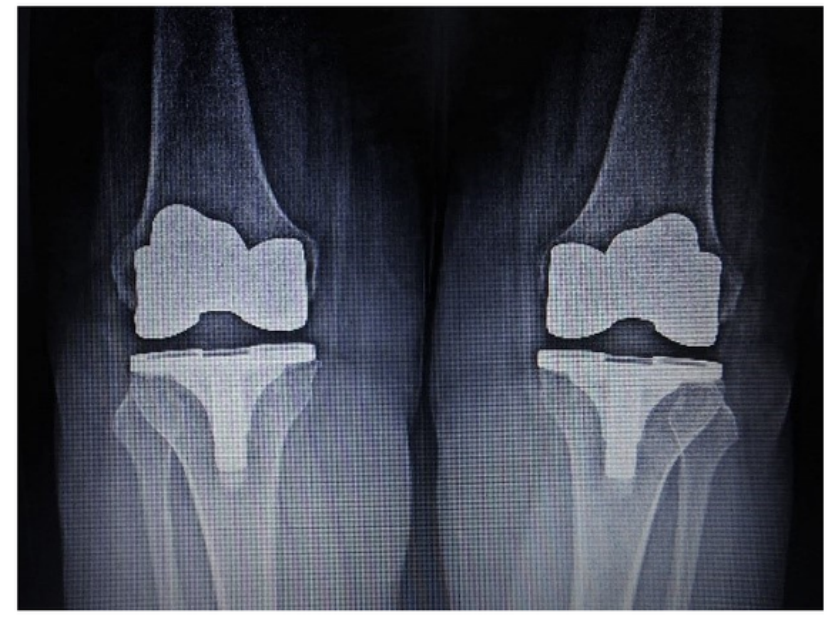

c

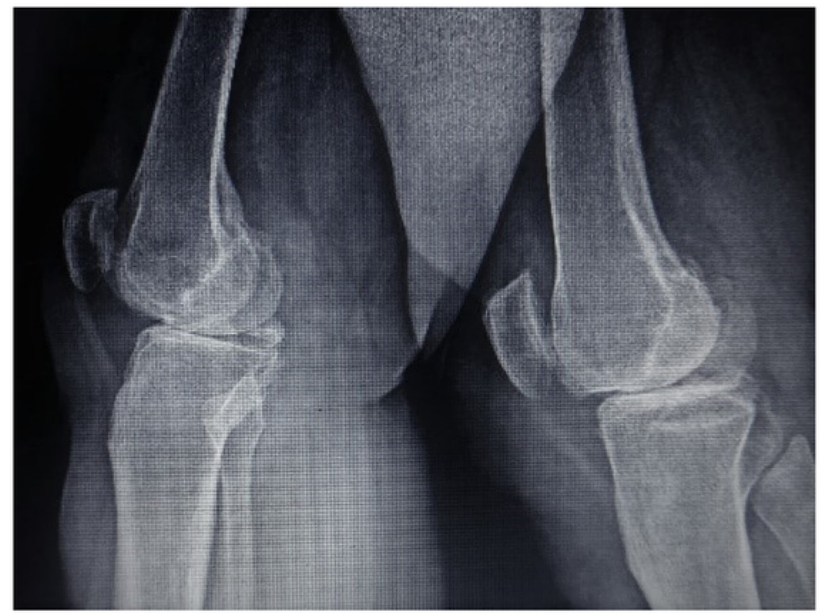

b

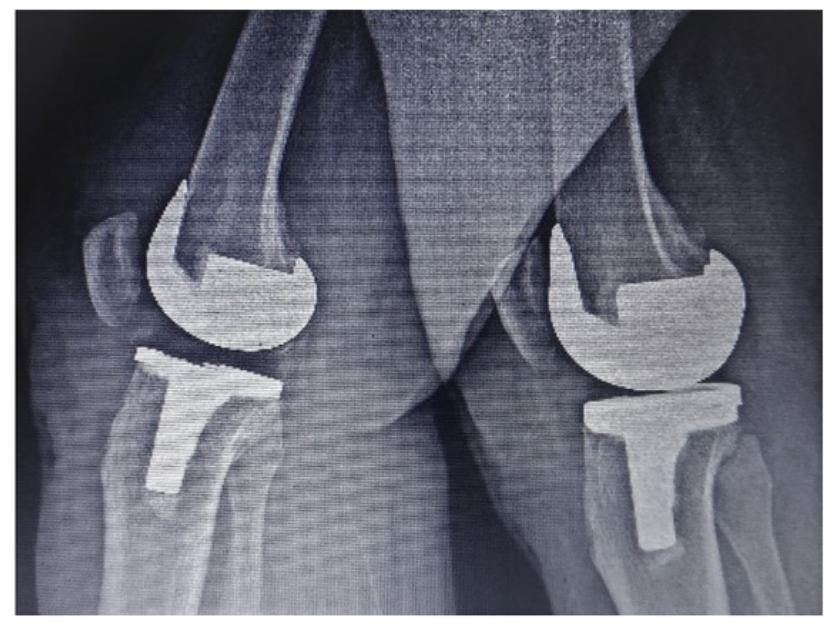

d

Figure 2

Photo 2(a-d): Sample preoperative and postoperative case graphics 


\section{Graph 1}

140

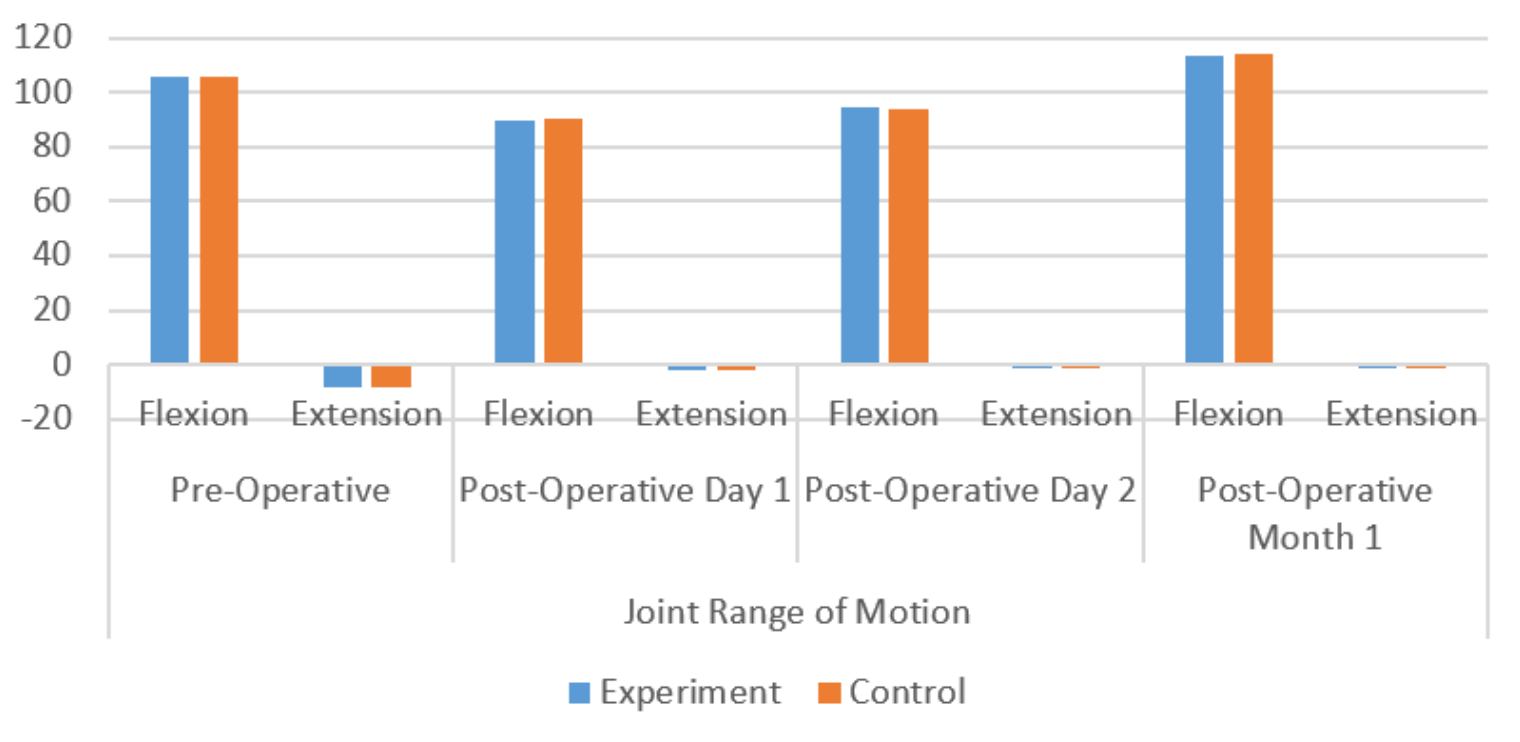

\section{Figure 3}

Graph 1: JRM over time EHA time distribution graph.

\section{Graph 2}

$$
5
$$

4.5

\section{4}

3.5

3

2.5

2

1.5

1

$-$

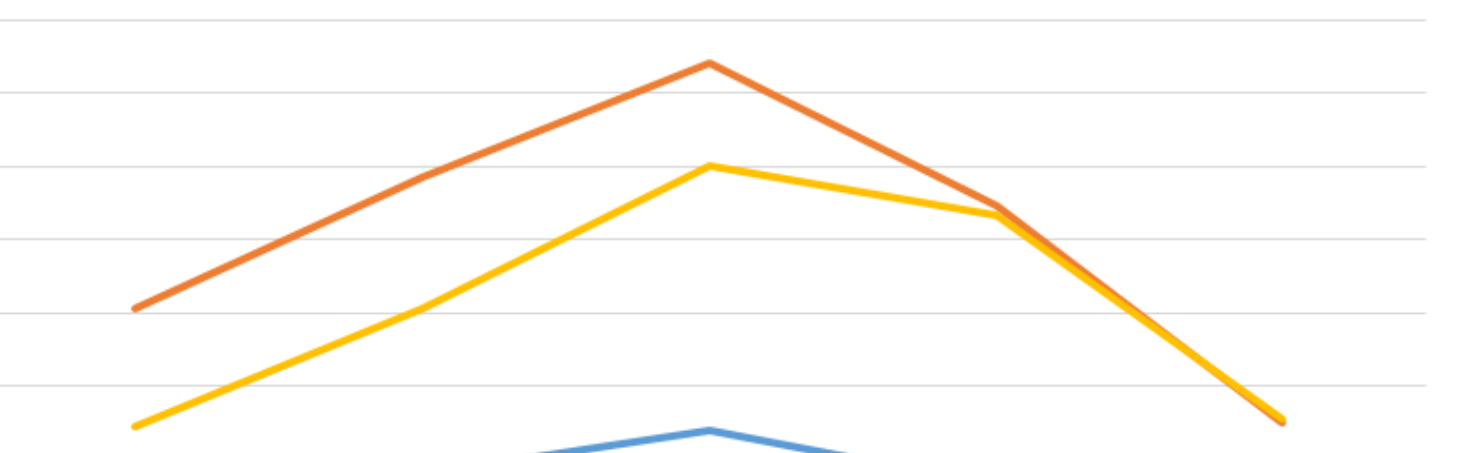

0.5

0
Post-Operative 2nd Post-Operative 8th Post-Operative 1st Post-Operative 2nd Post-Operative 1st Hour Hour Day Day
VAS Score Control Static
VAS Score Control Dynamic
VAS Score Experiment Static
-VAS Score Experiment Dynamic

\section{Figure 4}

Graph 2 Postoperative time graph of VAS scores Graph 2 shows the postoperative changes in the mean values of the control and experimental groups subject to time for VAS scores. 